\title{
Análise socio-espacial sobre alguns indicadores da educação pública no ensino fundamental do estado da Bahia
} brasileira, mais especificamente no que se refere ao ensino fundamental nos municípios baianos. O objetivo primaz é compreender quais as principais variáveis que influem na referida diferenciação. Partindo do Índice de Desenvolvimento da Educação Básica (Ideb) foi possível observar criticamente como este índice se relaciona com outras variáveis, sejam elas sócio-econômicas ou de cunho político-pedagógico, expondo pistas das possíveis causas dos resultados apontados pelo índice em cada realidade sócio-espacial baiana.

\section{Social-spatial analysis about some indicators of public education of the elementary school in Bahia state.}

Leandro Santos*

Lara Borowski*

Clímaco Dias**

* Graduandos em Geografia, licenciatura e bachareladoUFBA - Universidade Federal da Bahia

** Professor Assistente da Universidade Federal da Bahia.

\footnotetext{
Abstract: This paper is about the regional differentiation of the quality of brazilian education, more specifically, in the of the elementary school in municipalities of Bahia state. The central objective is to understand what are the main variables that intervene on the abovementioned differentiation. Taking as a starting point the IDEB (Basic Education Development Index) it was possible to critically observe the way by which this index is associated to other variables, such as, by one hand, the social and economical or, by the other hand, more political and pedagogical based. This helps to clarify the clues about the possible causes of the results obtained by the IDEB in each social-spatial reality of the Bahia state.
}

Palavras-chave:
Educação; Ideb;
Desenvolvimento; Análise
Regional.
Key-Words:
Education; Ideb;
Development; Regional
Analysis.




\section{Introdução}

A educação sempre foi vista como um dos principais vetores de mudanças e melhorias sociais e se mostra, cada vez mais, passível de ser utilizada como prática libertária, que auxilia na construção das diversas visões de mundo de cada indivíduo, os preparando para agir em sociedade. Mas para ampliar as potencialidades deste processo é necessária uma conjuntura favorável, com ações e políticas públicas adequadas.

E é por tal motivo que a questão demanda um amplo debate sobre como a educação é efetivamente encarada, seja pelos agentes públicos, seja por aqueles diretamente envolvidos no processo pedagógico, alunos, professores e gestores. Tal debate deve envolver ainda uma retomada de discussão dos próprios métodos utilizados pelo Sistema Nacional de Avaliação da Educação Básica (Saeb) e sua eficácia.

Todo estudo que tem como objetivo refletir a respeito das características da educação brasileira e suas variáveis insere-se em um terreno frágil, onde a cautela e a posição crítica se mostram imprescindíveis. Neste terreno somam-se ainda as contradições e mitificações criadas nos diferentes níveis de ensino que dificultam uma compreensão clara do tema.

A princípio deve-se entender de que forma o Índice de Desenvolvimento da Educação Básica (Ideb), insere-se no âmbito do Sistema de Avaliação da Educação Básica (Saeb). O referido indicador é um dos índices criados pelo Instituto Nacional de Estudos e Pesquisas Educacionais Anísio Teixeira (INEP) para compor o sistema avaliativo da qualidade da educação brasileira e é calculado a cada dois anos, a partir dos dados de aprovação escolar e de taxas de aprovação em exames do próprio INEP, como a Prova Brasil.

O índice possibilita ainda observações em escalas variadas, já que, além do Ideb nacional, existem ainda aqueles relativos às regiões, estados, municípios e escolas, públicas e privadas. Neste sentido, permite apreender quais as variáveis que influem em cada realidade específica e quais práticas possibilitam um processo de aprendizagem mais produtivo e eficaz. É a partir deste índice que muitas políticas públicas educacionais são planejadas e é também a partir dele que este estudo se inicia.

Entre os vários níveis de ensino que poderiam ser abordados para contextualização do tema, optou-se aqui por um caminho que tem como foco de análise as séries do Ensino Fundamental da Educação Básica na rede pública, que corresponde - ou deveria corresponder - à faixa etária de 6 a 14 anos.

Devemos assinalar que apesar do panorama introdutório referir-se ao cenário nacional trabalharemos com um enfoque maior no estado da Bahia e do Território de Identidade Metropolitano de Salvador (TIMS). O objetivo é sobrepor as escalas e analisar o fenômeno - a qualidade da Educação Básica - na sua totalidade para compreender como este mesmo fenômeno se realiza nas diferentes espacialidades e suas causas e conseqüências específicas.

\section{Um breve panorama nacional da educação básica}

Em estudo recente sobre os indicadores sociais brasileiros, o Instituto Brasileiro de Geografia e Estatística (IBGE) apresentou alguns resultados relevantes sobre os principais dados estatísticos referentes à realidade social brasileira, oriundos, principalmente, da Pesquisa Nacional por Amostra de Domicílios (Pnad), como também do INEP e outros órgãos de pesquisa nacionais. A maioria dos dados possibilita uma observação dos anos de 1999 a 2009. Entre estes dados destacam-se, para o interesse desta análise, aqueles referentes à Educação Básica no Brasil.

De acordo com o estudo a taxa de analfabetismo no Brasil, entre pessoas de 15 anos ou mais, passou de 13,3\% em 1999 para 9,7\% em 2009. Dentro do percentual de analfabetismo é

Geografia Ensino \& Pesquisa, v. 17, n.2 p.7287, mai/ago. 2013

Santos, L.; Borowski, L.; Dias, C.

ISSN 2236-4994 
possível traçar algumas características gerais:

$32 \%$ das pessoas analfabetas têm 60 anos ou mais de idade; $10,2 \%$ são pessoas de cor preta e 58,8\% pardas; $52,2 \%$ residem na Região Nordeste; e o fenômeno ocorre em $16,4 \%$ das pessoas que vivem com meio salário mínimo de renda familiar per capita. (IBGE, 2010).

Estes dados são fundamentais para entendermos como os avanços na área educacional se dão de forma heterogênea, mostrando claramente o perfil daqueles que não são assistidos pelas políticas públicas de educação.

No que se refere ao IDEB nacional, incluindo instituições públicas e privadas, das séries iniciais ( $1^{\mathrm{a}}$ a $4^{\mathrm{a}}$ série) do Ensino Fundamental, ocorreu uma evolução de 4,2 em 2007 para 4,6 em 2009. O mesmo índice correspondendo às séries finais ( $5^{\mathrm{a}}$ a $8^{\mathrm{a}}$ série) passou de $3,8 \mathrm{em}$ 2007 para 4,0 em 2009. Se observados separadamente, poderíamos inferir que os avanços não foram tão significativos, mas superaram as metas propostas, tanto em 2007, quanto em 2009.

Em linhas gerais percebe-se uma sensível melhoria no sistema educacional brasileiro, principalmente se levarmos em conta os índices de analfabetismo e o Ideb. A estes dados soma-se o fato de que somente a partir das últimas décadas se ampliaram as políticas públicas relativas à educação, a exemplo da criação em 1996 do Fundo de Manutenção e Desenvolvimento do Ensino Fundamental e Valorização do Magistério (Fundef), atual Fundo de Manutenção e Desenvolvimento da Educação Básica e de Valorização dos Profissionais da Educação (Fundeb), e o próprio Ideb, criado em 2007.

Vale lembrar que o índice em questão tenta mensurar a qualidade da Educação Básica, e que, se tratando de médias, a realidade nunca será contemplada como verdadeiramente se apresenta, decorrente das já conhecidas desigualdades sócio-espaciais do território brasileiro, que não são explicitadas claramente em números médios. Este é um ponto importante para a análise, pois não devemos perder de vista que o Ideb é uma avaliação quantitativa para uma questão invariavelmente qualitativa. Disso decorre o fato de não podermos balizar um estudo sobre Educação Básica apenas no índice em questão. Como dito, a realidade brasileira torna a tarefa de analisar a qualidade da Educação Básica ainda mais complexa frente às disparidades tão evidentes entre suas regiões, como nos mostra as Tabelas 1 e 2 :

Tabela 1: Ideb - Ensino Fundamental Regular (Séries iniciais) - 2009

\begin{tabular}{|c|c|}
\hline Região & Ideb \\
\hline Norte & 4,2 \\
\hline Nordeste & 3,7 \\
\hline Sudeste & 5,4 \\
\hline Sul & 4,9 \\
\hline Centro-Oeste & 5,0 \\
\hline
\end{tabular}

Fonte: INEP 2010, adaptado pelos autores.

Geografia Ensino \& Pesquisa, v. 17, n.2 p. 72-87, mai./ago 2013

Análise socio-espacial sobre alguns indicadores da educação pública no ensino fundamental do estado da Bahia
Tabela 2: Ideb - Ensino Fundamental Regular (Séries finais) - 2009

\begin{tabular}{|c|c|}
\hline Região & Ideb \\
\hline Norte & 3,5 \\
\hline Nordeste & 3,0 \\
\hline Sudeste & 4,1 \\
\hline Sul & 4,0 \\
\hline Centro-Oeste & 3,8 \\
\hline
\end{tabular}

Fonte: INEP 2010, adaptado pelos autores. 
Tanto nas séries iniciais quanto nas séries finais a região Sudeste aparece com os maiores índices; Já a região Nordeste do País aparece com o pior Ideb, o que nos leva a intuir que as disparidades econômicas e sociais das regiões brasileiras também afetam o quadro educacional.

Muito embora não pretendamos aprofundar a análise no bojo do quadro nacional, não podemos perder de vista que a regionalização aqui explicitada se faz necessária a fim de dar suporte e ajudar na visualização estatística dos dados. Porém, entende-se que o desenvolvimento desigual dos diferentes espaços regionais - pensando além de uma delimitação física - é resultado dos diferentes ritmos impostos ao longo da história a partir de relações sócioespaciais desiguais. E como já foi salientado anteriormente, a sobreposição das escalas é que nos permite entender quais as possíveis variáveis que diferenciam a qualidade da Educação Básica em toda a extensão do território nacional. Como nos alerta Santos e Elias:

A teorização depende de um esforço de generalização e de um esforço de individualização. A generalização nos dá a listagem das possibilidades; a individualização nos indica como, em cada lugar, algumas dessas possibilidades se combinam. (SANTOS e ELIAS, 1988, p. 21).

A perspectiva da quantidade de anos de estudo também é de fundamental importância para entender os reflexos da qualidade da educação brasileira em outros diferentes aspectos da dinâmica social. Somando-se o Ensino Fundamental e Médio chegamos a 11 anos de estudos necessários para que se possa garantir um ciclo educacional completo.

Em 2009 a média nacional de anos de estudo para a população na faixa de 15 anos ou mais foi de 7,5 anos. Aqui também a disparidade regional aparece: a população da região sudeste atingiu média de 8,2 anos de estudo, contrastando com a média de 6,7 da região nordeste.

É importante entender que o atraso do estudo nesta faixa etária repercutirá no futuro profissional desta população. Se considerarmos a faixa etária de 25 a 34 anos como sendo de grande relevância dentro da População Economicamente Ativa (PEA) perceberemos os claros reflexos do quadro educacional no setor econômico: Em 2009, aqueles que possuíam mais de 11 anos de estudo somavam 21,1\% da PEA; Aqueles com apenas 11 anos de estudo representavam 34,9\%; e os $44 \%$ restantes da PEA eram representados por aqueles que não conseguiram completar os 11 anos de estudo garantidos constitucionalmente. Temos, então, que a População Economicamente Ativa no Brasil é formada, em sua maioria, por mão-deobra não qualificada e sem a escolaridade básica, reflexo de um sistema educacional falho, que, em muitos casos, não possibilita a permanência dos alunos nas escolas.

Vale lembrar que, além de representarem um reflexo direto das falhas do sistema educacional brasileiro, os baixos índices de mão de obra qualificada no Brasil interferem nas dinâmicas migratórias e possibilitam a vinda de migrantes estrangeiros, que chegam ao país para atender a demanda por profissionais qualificados. Mesmo com a queda constante da taxa de desemprego da população na última década é necessário atentar para fatores outros, como o nível de qualificação e as condições reais de trabalho oferecidas nos diversos setores da economia brasileira. Enfatizamos aqui a importância de uma análise mais aprofundada de tais variáveis, mesmo que, aparentemente, os dados encontrados apontem para avanços.

\section{O IDEB nos territórios de identidade da Bahia}

Antes de iniciarmos a observação dos Índices de Desenvolvimento da Educação Básica nos Territórios de Identidade e nos municípios que os compõem, algumas questões relativas ao próprio processo de regionalização baiana - institucionalmente falando - devem ser pontuadas.

As análises regionais têm, historicamente, revelado importância, principalmente se

Geografia Ensino \& Pesquisa, v. 17, n.2 p.7287, mai/ago. 2013

Santos, L.; Borowski, L.; Dias, C. 
levarmos em conta as desigualdades do território baiano. Além de possuir grande extensão - é o $5^{\circ}$ maior estado do Brasil, em área - possui uma grande diversidade de regiões naturais e diferenciações sociais e econômicas próprias da formação histórica do seu território. É de acordo com estas primeiras considerações que inferimos a importância de uma análise no âmbito regional baiano e, como conseqüência direta, uma regionalização coerente com tais diferenciações.

Se pensarmos na importância das análises regionais, não só para o estado da Bahia, mas para todo o território nacional, perceberemos que inúmeras políticas públicas surgiram e ainda surgem desta escala de abordagem. Basta pensar nas superintendências regionais, tais como a SUDAM (Superintendência de Desenvolvimento da Amazônia), SUDECO (Superintendência de Desenvolvimento do Centro-Oeste), SUDENE (Superintendência de Desenvolvimento do Nordeste), entre outras. Vale lembrar que tais superintendências surgiram com a justificativa de promover um desenvolvimento regional includente e sustentável, mas, em muitos casos, são passíveis de questionamentos em relação a sua relevância e eficácia.

O arranjo político e administrativo brasileiro se estabelece em três principais níveis distintos, como afirmam Sylvio Bandeira de Mello e Silva e Bárbara Christine Nentwig Silva: há no Brasil "três níveis político-administrativos historicamente estabelecidos, o nível federal, o nível estadual e o nível municipal". (SILVA e SILVA, 2003, p.77). Mas estes níveis não contemplam sozinhos e isoladamente a realidade brasileira da melhor forma, devido as suas já citadas disparidades regionais. É por isso, novamente, que a escala regional merece destaque.

No que se refere às regionalizações internas de um estado da federação as considerações são as mesmas. Sylvio Bandeira e Bárbara Christine Nentwig reforçam a necessidade de uma instância ao mesmo tempo supra-municipal e subestadual, pois "para muitos aspectos, o nível estadual seria muito amplo e o nível municipal seria, por sua vez, muito pequeno". (SILVA e SILVA, 2003, p. 77)

No caso baiano os diversos processos de regionalização resultaram, no ano de 2010, no decreto 12354 que institui os Territórios de Identidade (T.I.). De acordo com o decreto, o Território de Identidade se constitui como:

Agrupamento identitário municipal formado de acordo com critérios sociais, culturais, econômicos e geográficos e reconhecido pela sua população como o espaço historicamente construído ao qual pertence, com identidade que amplia as possibilidades de coesão social e territorial. (BAHIA, 2010).

Geografia Ensino \& Pesquisa, v. 17 , n.2 p. 72-87, mai./ago 2013

Análise socio-espacial sobre alguns indicadores da educação pública no ensino fundamental do estado da Bahia
O regionalismo parte da base, vem de baixo, emerge da consciência das desigualdades regionais e é a contestação ao centralismo, a luta pela autonomia. Já a regionalização vem de cima, é a aceitação do centralismo e a perda do poder decisório. (BEZZI, 2004, p. 216).

Entende-se aqui, portanto, que os processos de regionalização, em sua maioria, representam uma delimitação externa à própria região e que, em muitos casos, tem por base 
critérios econômicos ou político-administrativos, negligenciando a própria noção de identidade cultural pertencente a cada região.

É neste contexto que os Territórios de Identidade, criados pelo Governo Estadual, aparecem como tentativa de uma regionalização diferenciada, que se aproxime das identidades regionalistas, buscando atentar para os aspectos sócio-culturais, além daqueles políticoeconômicos. Apesar da proposta diferenciada, muitas ressalvas têm sido feitas a esta regionalização, principalmente por não haver clareza com relação aos critérios que definem a inclusão dos municípios em territórios específicos, questionando a priorização dos aspectos identitários. Para uma análise mais aprofundada deste processo de regionalização e seus rebatimentos sócio-espaciais é necessário, então, um amplo debate sobre os conceitos de identidade cultural, território e região. Não iremos nos ater profundamente a este debate, mas ratificamos a sua importância para as questões de planejamento e gestão territorial.

Figura 1- Territórios de Identidade - Bahia

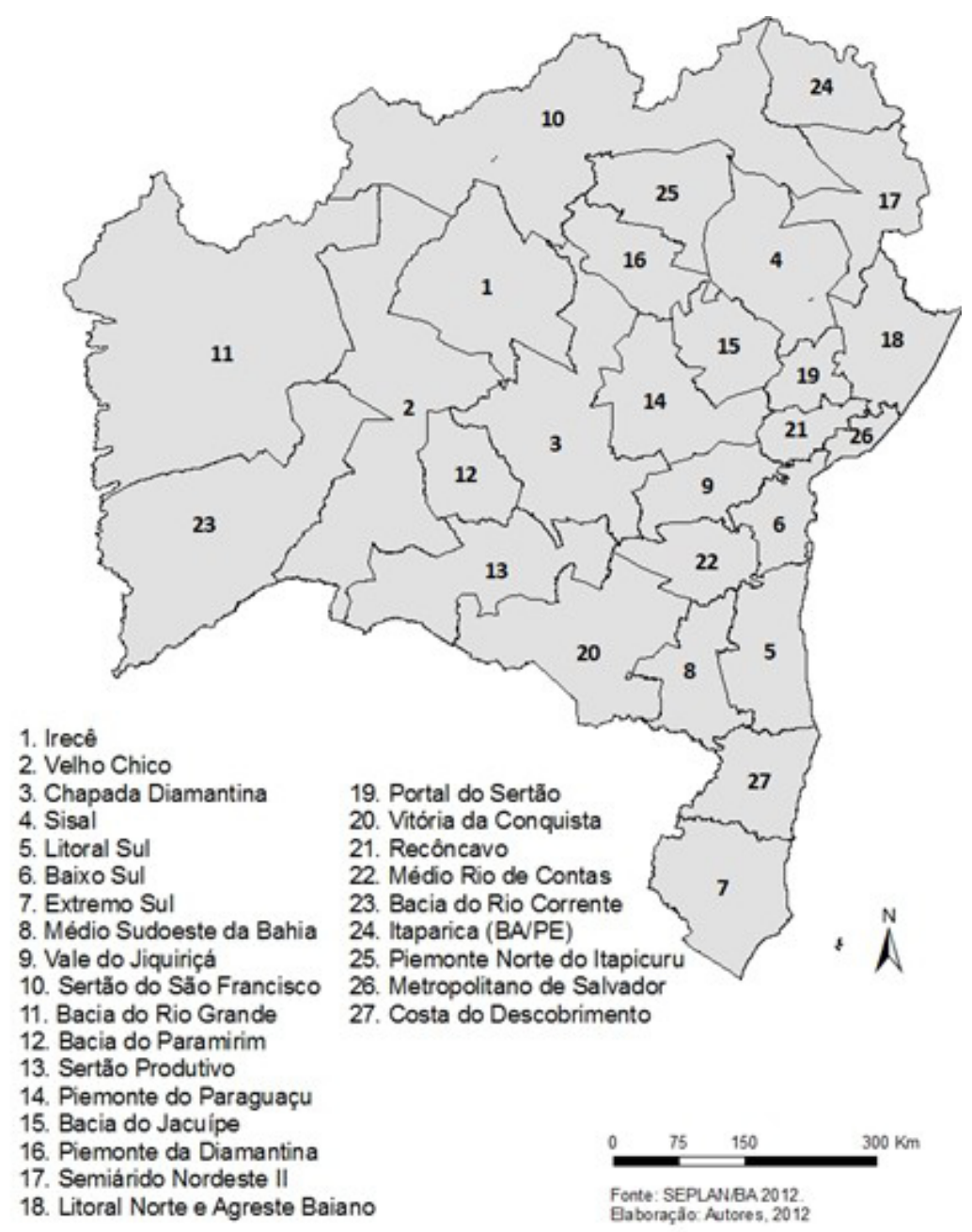

Para o estudo em questão utilizaremos os Territórios de Identidade por constituírem a regionalização baiana utilizada pelo Estado, e que, portanto, possui aplicações políticoadministrativas no que se refere ao planejamento regional baiano. Nesta seção, tentaremos focar nos T.I. de maior destaque para a dinâmica educacional, através da Figura 2 e das tabelas que se seguem, contemplando as variáveis sócio-econômicas de cada um deles.

Através dos mapas e da listagem de notas municipais no Ideb, é possível constatar que há maior concentração de índices altos nos Territórios de Identidade da Chapada Diamantina, Sertão Produtivo, Piemonte da Diamantina, Portal do Sertão e Piemonte do Paraguaçu, assim como há predomínio de baixos índices no território Médio Rio das Contas.

Vale destacar que são nas séries iniciais que a Bahia aparece com o pior desempenho,

Geografia Ensino \& Pesquisa, v. 17 , n.2 p.7287, mai/ago. 2013

Santos, L.; Borowski, L.; Dias, C. 
Territórios de Identidade: 1. Irecê; 2.Velho Chico; 3. Chapada Diamantina; 4. Sisal; 5. Litoral Sul; 6. Baixo Sul; 7. Extremo Sul; 8. Médio Sudoeste da Bahia; 9. Vale do Jiquiriçá; 10. Sertão do São Francisco; 11. Bacia do Rio Grande; 12. Bacia do Paramirim; 13. Sertão Produtivo; $14 . \quad$ Piemonte do Paraguaçu; 15. Bacia do Jacuípe; 16. Piemonte da Diamantina; 17. Semiárido Nordeste II; 18. Litoral Norte e Agreste Baiano; 19. Portal do Sertão; 20. Vitória da Conquista; 21. Recôncavo; 22. Médio Rio de Contas; 23. Bacia do Rio Corrente; 24. Itaparica; 25. Piemonte Norte do Itapicuru; 26. Metropolitano de Salvador; 27. Costa do Descobrimento.

Geografia Ensino \& Pesquisa, v. 17 , n.2 p. 72-87, mai./ago 2013

Análise socio-espacial sobre alguns indicadores da educação pública no ensino fundamental do estado da Bahia frente ao cenário nacional: em todo o Brasil, das cinco piores notas no IDEB, seis municípios são baianos (tabela 3). Além disso, dos 98 municípios que possuem as 10 piores notas no Ideb nas séries iniciais, 83 são da região Nordeste e 15 da região Norte do país, o que atesta, novamente, as disparidades regionais citadas na seção anterior.

Figura 2- IDEB nos Territórios de Identidade $(\mathrm{BA})^{1}$
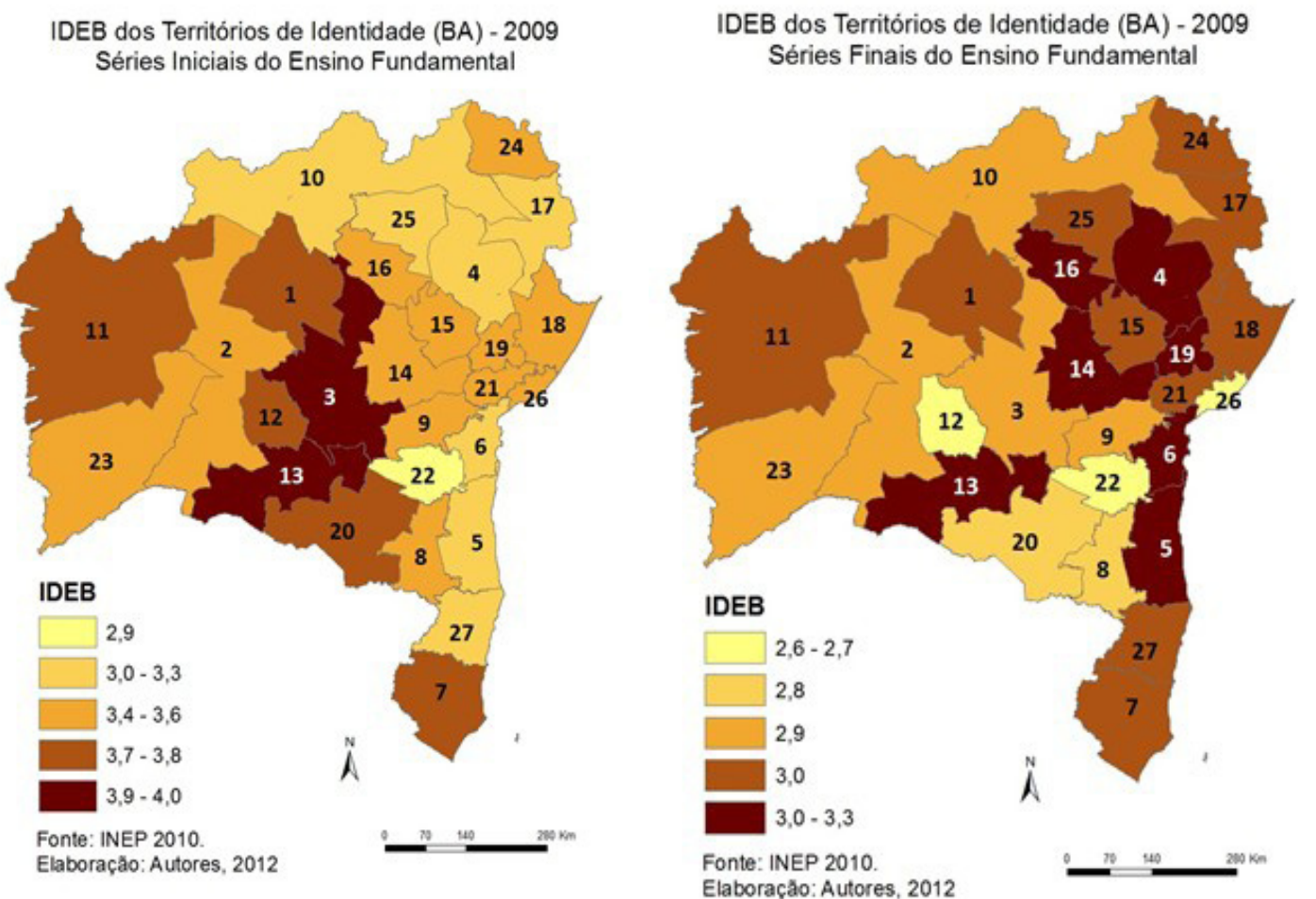

Tabela 3- Municípios Brasileiros - Piores notas no Ideb

\begin{tabular}{|c|c|}
\hline Município & Ideb (Séries Iniciais) 2009 \\
\hline Apuarema (BA) & 0,5 \\
\hline Chaves (PA) & 1,4 \\
\hline Pedro Alexandre (BA) & 2,0 \\
\hline Manoel Vitorino (BA) & 2,1 \\
\hline Nilo Peçanha (BA) & 2,1 \\
\hline Bonfim do Piauí (PI) & 2,2 \\
\hline São Félix do Piauí (PI) & 2,2 \\
\hline Duas Estradas (PB) & 2,2 \\
\hline Santa Inês (PB) & 2,2 \\
\hline Dario Meira (BA) & 2,2 \\
\hline Pilão Arcado (BA) & 2,2 \\
\hline
\end{tabular}

Fonte: INEP 2010, adaptado pelos autores.

Limitaremos a análise aos municípios dos Territórios de Identidade da Chapada Diamantina e Médio Rio de Contas e suas variáveis sócio-econômicas e educacionais, para que possamos compreender as possíveis causas desta diferenciação.

Dos 24 municípios que compõem o Território da Chapada Diamantina, 19 possuem Ideb maior ou igual que a média estadual, de 3,5 nas séries iniciais. Vale destacar que o melhor Ideb do estado nas séries finais pertence à Ibitiara; e Piatã possui o segundo maior Ideb do estado, nas séries iniciais (tabela 4). 
Tabela 4 -Território de Identidade Chapada Diamantina

\begin{tabular}{|c|c|c|}
\hline Município & Ideb (Séries Iniciais) 2009 & Ideb (Séries Finais) 2009 \\
\hline Abaíra & 4,3 & 3,4 \\
\hline Barra da Estiva & 4,3 & 3,6 \\
\hline Ibitiara & 5,0 & 4,6 \\
\hline Piatã & 5,3 & 3,6 \\
\hline
\end{tabular}

Fonte: INEP 2010, adaptado pelos autores.

Em contrapartida, entre as 10 piores notas no Ideb, tanto nas séries iniciais quanto nas finais, estão quatro municípios do Território Médio Rio de Contas. Os municípios de Dário Meira e Manoel Vitorino aparecem nas duas listagens, entre as piores notas. Os piores índices do Território Médio Rio de Contas estão listadas na Tabela 5.

Tabela 5- Território de Identidade Médio Rio de Contas

\begin{tabular}{|c|c|c|}
\hline Município & Ideb (Séries Iniciais) 2009 & Ideb (Séries Finais) 2009 \\
\hline Apuarema & 0,5 & 2,6 \\
\hline Dário Meira & 2,2 & 2,1 \\
\hline Ibirataia & 3,2 & 1,9 \\
\hline Itamari & 2,3 & 2,6 \\
\hline Manoel Vitorino & 2,1 & 1,8 \\
\hline
\end{tabular}

Fonte: INEP 2010, adaptado pelos autores.

Relativa à tabela acima vale fazer uma ressalva: A Secretaria Municipal de Educação de Apuarema, município que aparece com a nota 0,5 nas séries iniciais afirmou que houve falha no envio das notas escolares para o sistema nacional dos dados, o que fez com que a nota final do município aparecesse tão baixa. Somente um ano depois o INEP, instituto responsável pela divulgação dos resultados, corrigiu a nota do município, que passou para 2,4.

O seguinte questionamento norteará nossas observações acerca do tema: Em qual intensidade as condições sócio-econômicas dos Territórios e municípios em destaque influenciam na diferenciação do Ideb? A influência exercida por estas variáveis é mais relevante do que aquela exercida pelos princípios pedagógicos utilizados nas instituições escolares?

No que se refere ao Índice de Desenvolvimento Social(IDS) e ao Produto Interno Bruto(PIB), o Território Médio Rio de Contas apresenta maiores valores do que aqueles relativos ao Território da Chapada Diamantina (tabelas 6 e 7).

Tabela 6- Território de Identidade Chapada Diamantina

\begin{tabular}{|c|c|}
\hline IDS (média territorial) 2006 & PIB Territorial (R\$ milhão) 2008 \\
\hline $4.992,5$ & $1.755,90$ \\
\hline
\end{tabular}

Fonte: SEI 2010b, adaptado pelos autores.

Tabela 7- Território de Identidade Médio Rio de Contas

\begin{tabular}{|c|c|}
\hline IDS (média territorial) 2006 & PIB Territorial (R\$ milhão) 2008 \\
\hline $4.993,01$ & $2.250,16$ \\
\hline
\end{tabular}

Fonte: SEI 2010b, adaptado pelos autores.

As tabelas acima apontam para uma relativização da importância do aspecto econômico no que se refere aos resultados educacionais. Além dos dados acima apresentados alguns outros territórios com altos valores de PIB não alcançam notas altas no Ideb, assim como

Geografia Ensino \& Pesquisa, v. 17, n.2 p.7287, mai/ago. 2013

Santos, L.; Borowski, L.; Dias, C.

ISSN $2236-4994$ 
territórios que apresentam baixo valor de PIB alcançam notas muito mais significativas do que o território em questão. A título de comparação, o Território de Identidade de Irecê apresentou PIB Territorial (2008) de R $\$ 1.452,22$, e dos 20 municípios que o compõem, 14 apresentaram Ideb maior que a média estadual, de 3,5 nas séries iniciais.

As variáveis sócio-econômicas, como PIB e IDS devem ser relativizadas porque não se apresentam de forma isolada, muito menos de forma determinista. Evidencia-se, então, a existência de outras variáveis por trás da qualidade educacional. E acreditamos que elas se referem, principalmente, às instâncias mais locais, tais como a gestão municipal da educação e os projetos político-pedagógicos das instituições de ensino.

O município de Ibitiara, inserido no Território da Chapada Diamantina, e anteriormente citado por possuir o melhor Ideb do Estado nas séries finais, obteve destaque em um estudo realizado pelo Ministério da Educação (MEC) em 2011. O destaque decorre do sucesso de suas atividades pedagógicas, principalmente no que se refere ao Horário de Trabalho Pedagógico Coletivo (HTPC) que, de acordo com o Plano Nacional da Educação (PNE) de 2001, deveria ocorrer em todas as unidades escolares, mas que, em muitos casos torna-se improdutivo e ineficaz.

No caso do município de Ibitiara foi observado um planejamento efetivo em relação ao HTPC e na formação dos professores, dois vetores de mudanças importantes na qualidade do ensino. O planejamento eficaz demanda, sobretudo, regularidade nas reuniões, avaliação dos planos e uma relação de comprometimento entre os projetos da Secretaria da Educação do município, coordenadores pedagógicos e professores.

Em pesquisa intitulada "Redes de Aprendizagem: Boas práticas de municípios que garantem o direito de aprender", o MEC, com apoio de outras instituições voltadas para o tema, pretendeu evidenciar práticas pedagógicas de redes municipais de ensino em todo o Brasil que desafiam os entraves político-econômicos locais e garantem o direito de aprender de todos os alunos. Entre as práticas evidenciadas estão, por exemplo, a valorização da leitura, o comprometimento com a formação profissional dos docentes, a atenção oferecida individualmente a cada aluno e a aproximação entre as escolas e os familiares. O estudo parte das redes municipais de ensino para a construção do conceito de Redes de Aprendizagem. Tais redes, segundo o estudo, possuem um propósito em comum, a aprendizagem:

[...] trabalham numa dinâmica de troca e fluxo de informação, que gera um clima de compromisso de toda a comunidade com as questões locais e com a qualidade da educação. O aluno não é só aluno de uma professora. É aluno da rede. O professor não está sozinho. É parte da equipe da escola e da rede. (MEC, 2008)

Geografia Ensino \& Pesquisa, v. 17 , n.2 p. 72-87, mai./ago 2013

Análise socio-espacial sobre alguns indicadores da educação pública no ensino fundamental do estado da Bahia
A organização em redes aplicada no contexto educacional apresentou aspectos positivos que produziram uma nova dinâmica local, envolvendo a comunidade, dirigentes da rede municipal, professores e alunos, em um sentido amplo de colaboração.

Duas das 37 redes analisadas pertencem a municípios baianos, Presidente Dutra, no Território de Irecê e Mortugaba, no Território de Vitória da Conquista. O município de Mortugaba possui 37 escolas de Ensino Fundamental, incluindo escolas rurais e urbanas e possui a segunda melhor nota no Ideb nas séries iniciais. Seu principal destaque é o planejamento semanal regular do programa pedagógico, que envolve professores, diretores e coordenadoras pedagógicas da Secretaria Municipal. Com o planejamento em dia é possível colocar em prática projetos interdisciplinares e de incentivo a leitura e a criatividade dos alunos.

Mais do que os índices econômicos, a autonomia nas gestões municipais e escolares é de fundamental importância: 
Os Sistemas Municipais de Ensino [...] pressupõem uma estrutura institucional, composta, necessariamente, das unidades escolares, de um órgão executivo e de um órgão normativo. Como eles têm autonomia para elaborar normas complementares às normas nacionais e para adaptálas ao contexto local, em geral a organização desses sistemas dá agilidade às decisões do município, que não precisam ser submetidas ao Conselho Estadual de Educação ou a outras instâncias deliberativas. (MEC, 2008)

Entretanto, os avanços oriundos da autonomia municipal, assim como as boas práticas pedagógicas não devem ser pontuais e isoladas. Daí advém a importância de uma regionalização que leve em conta as diferentes dinâmicas municipais, através de um planejamento participativo, para que tais práticas se estendam por uma região mais ampla.

Em Presidente Dutra, que obteve nota 4,1 nas séries finais, foi observada uma preocupação com a formação dos docentes, mas que só foi posta em prática a partir do auxílio do governo estadual e federal. Em 2007, ano em que a pesquisa foi realizada, os docentes da rede municipal só possuíam o Ensino Médio completo, mas 80\% deles estudavam em faculdades, com o auxílio da Secretaria Municipal de Educação:

$\mathrm{Na}$ falta de recursos próprios, a Secretaria Municipal de Educação de Presidente Dutra desenvolve projetos de formação com a participação dos governos federal e do estado da Bahia. O município já realizou diversos programas, dentre eles o Gestão de Aprendizagem Escolar (Gestar) e o Programa de Formação de Professores em Exercício (Proformação). Hoje, oferece a 70 professores o Programa Mobilização pela Qualidade da Educação (Pró-Letramento) e apóia a realização de cursos com recursos do Plano de Desenvolvimento da Escola. (MEC, 2008)

Este fato demonstra que a autonomia municipal é um dos aspectos fundamentais para um melhor desenvolvimento educacional, mas que depende também de redes integradas que facilitem determinadas práticas. Afinal, este é um dos pontos básicos para se alcançar um desenvolvimento regional includente, nos mais variados aspectos. A cooperação entre os gestores municipais dos Territórios de Identidade, no caso baiano, é imprescindível para que as boas práticas se difundam, formando, verdadeiras "redes de aprendizagem".

\section{O caso do território de identidade metropolitano de Salvador}

De acordo com o último censo demográfico (2010) o Território de Identidade Metropolitano de Salvador (TIMS) ${ }^{2}$ apresentou em sua totalidade uma população de 3.439.670 habitantes, distribuídos heterogeneamente pelos 10 municípios que compõem a área em questão, o que corresponde a aproximadamente $25 \%$ da população total do estado.

Para o ano de 2009 o PIB a preços correntes (em milhões) do TIMS correspondia a R \$ $58.285,88$, aproximadamente $42 \%$ do PIB estadual que para o mesmo período correspondia a 137.074,67, o que juntamente com os dados populacionais expressam a importância que a região em evidência possui no estado, com destaque para sua capital que, como tal, constitui uma forte centralidade, apresentando-se, atualmente, como a terceira maior cidade do Brasil, em termos demográficos, perdendo apenas para São Paulo e Rio de Janeiro. Dessa forma, Salvador coloca-se no cenário nacional como uma complexa e problemática metrópole brasileira e, como salienta Milton Santos,

\footnotetext{
2 Por uma opção metodológica este estudo toma por base comparativa a regionalização dos Territórios de Identidade da Bahia e, portanto, também o Território de Identidade Metropolitano de Salvador. Neste caso cabe, entretanto, uma breve ressalva: Dos 27 T.I. instituídos, este é o que apresenta maiores fragilidades, já que existem fatores específicos que identificam uma relação metropolitana que não são utilizados na definição do Território de Identidade. Disto decorre o fato de que o Território Metropolitano de Salvador é composto por 10 municípios que não coincidem totalmente com aqueles da Região Metropolitana de Salvador, composta por 13 municípios.
}

Geografia Ensino \& Pesquisa, v. 17, n.2 p.7287, mai/ago. 2013

Santos, L.; Borowski, L.; Dias, C.

ISSN 2236-4994 
O crescimento metropolitano resulta de um conjunto de processos sistematicamente interligados, entre os quais a integração do território, a desarticulação das economias tradicionais e dos cimentos regionais, os novos papéis da circulação no processo produtivo, o desencadeamento de grandes correntes migratórias, paralelamente ao processo de concentração das rendas. (SANTOS, 1990, p. 47)

Diante desses dados - e pensando além deles -, não podemos deixar de refletir sobre as mudanças qualitativas de toda ordem que se expressam no espaço metropolitano decorrentes das dinâmicas próprias dessa escala de abordagem.

Atendo-se a isso, voltemos agora nosso olhar para analisar como o Índice de Desenvolvimento da Educação Básica se expressa na região supracitada, através da Figura 3 e da Tabela 8, apoiando-se também em outros indicadores que auxiliam, de certa forma, na compreensão das realidades dadas.

Figura 3:-Ideb no T. I. Metropolitano de Salvador (BA) - Séries Iniciais

\section{Território de Identidade Metropolitano de Salvador (BA) IDEB 2009 - Séries Iniciais do Ensino Fundamental}

Geografia Ensino \& Pesquisa, v. 17, n.2 p. 72-87, mai./ago 2013

Análise socio-espacial sobre alguns indicadores da educação pública no ensino fundamental do estado da Bahia

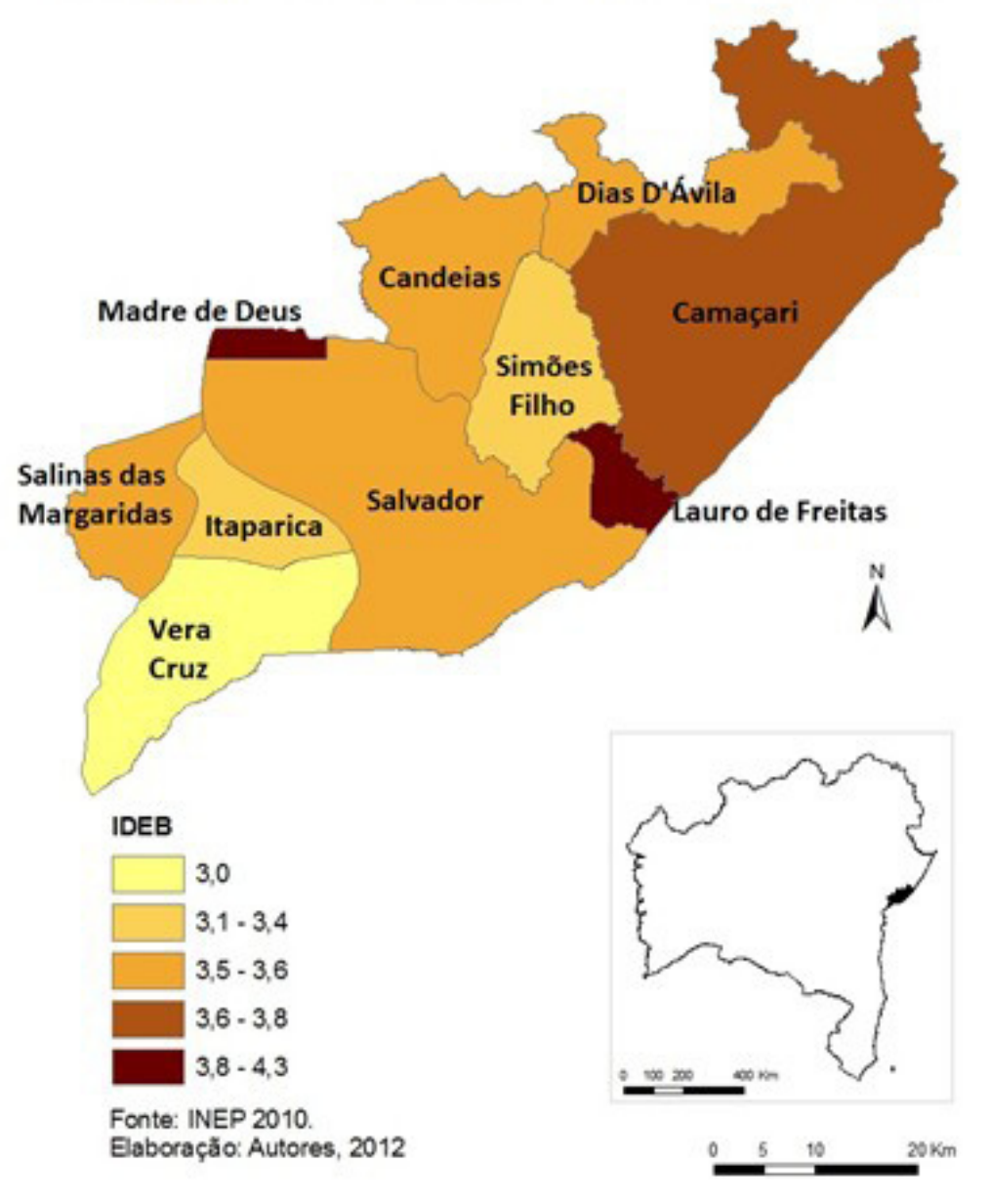

Para o TIMS, os resultados do Ideb de 2005 (série histórica), 2007 e, o mais recente, de 2009 das séries iniciais mostram algumas questões que merecem ser discutidas:

Percebe-se, na maioria dos municípios, uma clara evolução nos índices ao longo dos anos, tendo entre 2007 e 2009 apenas os municípios de Vera Cruz, Dias D’Ávila e Salinas das Margaridas estagnados na mesma nota. Iremos aqui levantar algumas considerações. 
Tabela 8-Ideb - Ensino Fundamental (Séries Iniciais) - 2005 - 2009

\begin{tabular}{|c|c|c|c|}
\hline Município & Ideb 2005 & Ideb 2007 & Ideb 2009 \\
\hline Camaçari & 2,6 & 2,9 & 3,8 \\
\hline Candeias & 3,0 & 3,0 & 3,5 \\
\hline Dias D'Ávila & 2,8 & 3,6 & 3,6 \\
\hline Itaparica & 2,3 & 3,1 & 3,2 \\
\hline Lauro de Freitas & 3,2 & 3,6 & 4,1 \\
\hline Madre de Deus & 3,6 & 3,8 & 4,3 \\
\hline Salinas das Margaridas & 2,7 & 3,6 & 3,6 \\
\hline Salvador & 2,8 & 3,5 & 3,6 \\
\hline Simões Filho & 2,8 & 3,2 & 3,4 \\
\hline Vera Cruz & 2,6 & 3,0 & 3,0 \\
\hline
\end{tabular}

Fonte: INEP 2010, adaptado pelos autores

Ao contrário do que se poderia imaginar a cidade de Salvador apresenta resultados pouco significativos em relação aos outros municípios que compõem o território de identidade em destaque. Podemos perceber que nos três anos mencionados, os municípios de Lauro de Freitas e Madre de Deus se destacam com os melhores índices.

É evidente que se tomarmos esses dados isolados, não contextualizando com outras escalas de análise que se sobrepõem, poder-se-ia criar mitificações. Daí a importância de observar esses dados inseridos no contexto da Bahia e do Brasil. Primeiramente, comecemos com Salvador. Tomando por base o último resultado do Ideb, para o ano de 2009, a capital baiana apresentou resultado de 3,6 - acima da média estadual que para o mesmo ano foi de 3,5 , e abaixo da média nacional que foi de 4,4. No que se refere às capitais brasileiras Salvador encontra-se entre os piores índices, juntamente com Aracaju e Maceió, ambos com 3,6.

Os municípios com as melhores notas, Madre de Deus e Lauro de Freitas apresentaram resultados maiores que a média para o estado, juntamente com Camaçari, que entre os anos de 2007 e 2009 também apresentou melhoria significativa no seu índice, equiparando-se a média estadual para o ano de 2009. Ainda assim, existe uma distância considerável entre os resultados dos municípios citados em relação ao melhor resultado do estado, pertencente ao município de Boa Vista do Tupim, que apresentou para o ano de 2009 o Ideb de 5,8 - meta estipulada para o Brasil em 2021.

Evidente que se tratando de ensino e por ser um tema repleto de variáveis a questão se mostra bastante complexa. Examinemos por agora o que os dados relativos às séries finais do ensino fundamental podem revelar:

Tabela 9-IDEB - Ensino Fundamental (Séries Finais) - 2005 - 2009

\begin{tabular}{|c|c|c|c|}
\hline Município & Ideb 2005 & Ideb 2007 & Ideb 2009 \\
\hline Camaçari & 2,3 & 2,6 & 3,3 \\
\hline Candeias & 2,4 & 2,6 & 2,8 \\
\hline Dias D'Ávila & 2,1 & 2,4 & 2,3 \\
\hline Itaparica & 2,2 & 2,7 & 2,6 \\
\hline Lauro de Freitas & 2,7 & 2,5 & 3,2 \\
\hline Madre de Deus & 2,5 & 2,7 & 3,3 \\
\hline Salinas das Margaridas & 2,4 & 2,5 & 2,9 \\
\hline Salvador & 2,5 & 2,7 & 2,7 \\
\hline Simões Filho & 2,6 & 2,7 & 2,6 \\
\hline Vera Cruz & 2,1 & 1,9 & 2,5 \\
\hline
\end{tabular}

Geografia Ensino \& Pesquisa, v. 17, n.2 p.7287, mai/ago. 2013

Santos, L.; Borowski, L.; Dias, C. 
Figura 4- Ideb no T. I. Metropolitano de Salvador (BA) - Séries Finais

\section{Território de Identidade Metropolitano de Salvador (BA) IDEB 2009 - Séries Finais do Ensino Fundamental}

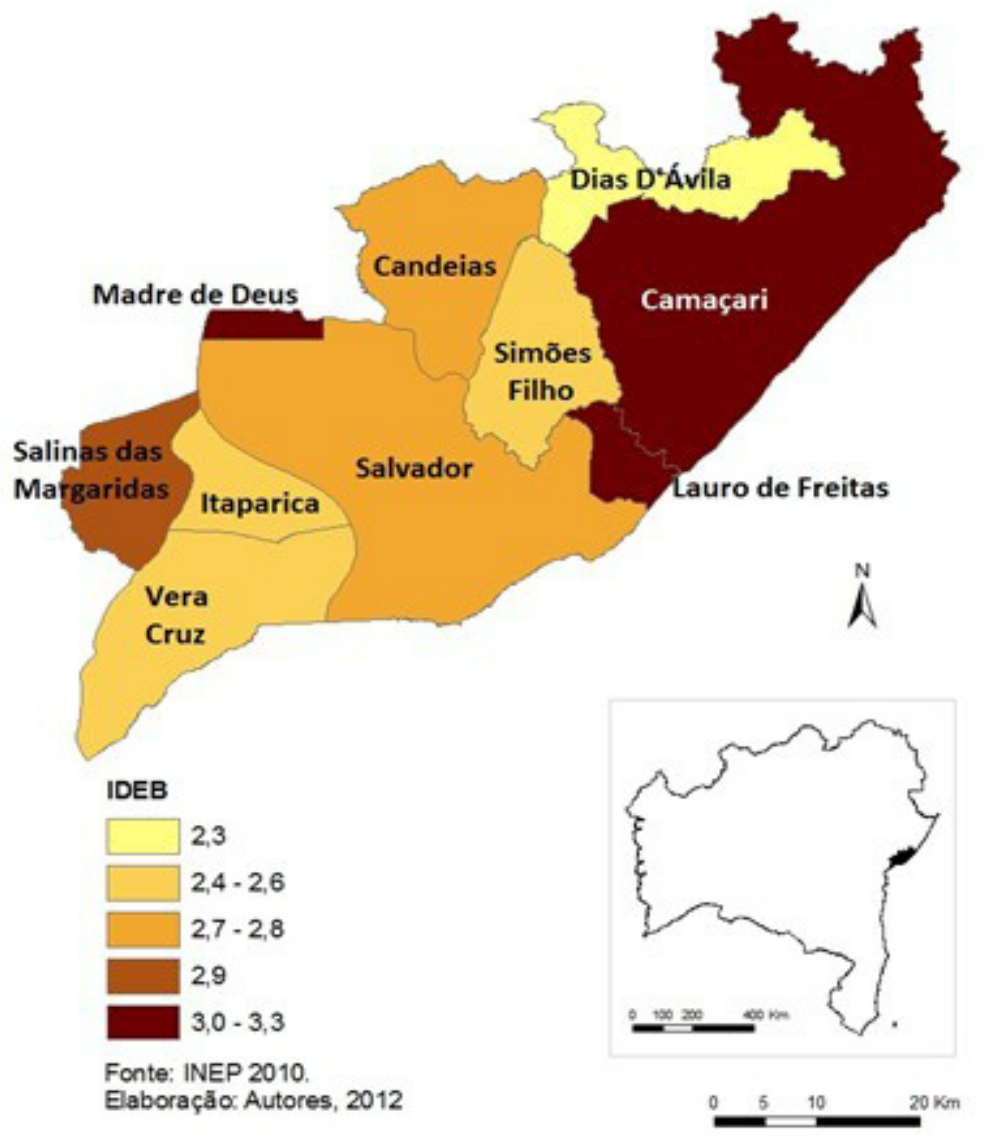

Os resultados supracitados demonstram a princípio uma realidade que se aplica em geral ao Brasil, pois aqui também as médias referentes aos anos finais de estudo do Ensino Fundamental se mostram mais baixas que os anos iniciais. Todavia, a tabela 9 nos revela outras informações que merecem ser mencionadas. Se percebermos com atenção nota-se que, no tocante às melhores médias, assim como às séries iniciais, temos entre as melhores os municípios de Lauro de Freitas e Madre de Deus, porém, encontramos para os anos de 2005 e 2007 municípios como Salvador, Simões Filho, Salinas das Margaridas, Itaparica, Candeias e Camaçari que não apresentam diferença tão significativa em relação às melhores mencionadas, até mesmo chegando a obter melhor média em algum desses anos. Apesar disso, se direcionarmos o nosso olhar para o último ano (2009), nota-se claramente que são elas, Lauro de Freitas, Madre de Deus, juntamente com Camaçari que apresentam as melhores médias, e aqui uma observação deve ser ressaltada: assim como para os anos iniciais, é entre os anos de 2007 e 2009 que Camaçari apresenta saltos quantitativos significativos, passando

Geografia Ensino \& Pesquisa, v. 17 , n.2 p. 72-87, mai./ago 2013

Análise socio-espacial sobre alguns indicadores da educação pública no ensino fundamental do estado da Bahia de 2,6 a 3,3 .

Contextualizando novamente com o território nacional, no que se refere a Salvador, percebe-se que o município, em 2009, alcançou Ideb de 2,7, abaixo da nota estadual que para o mesmo ano foi de 2,9 e muito abaixo da média nacional que foi de 3,7. Relativamente às capitais brasileiras, Salvador tem Ideb maior apenas que Maceió, com 2,6. Já os outros municípios que na nossa análise alcançam relevo, Madre de Deus, Lauro de Freitas e Camaçari, assim como para os anos iniciais, estes apresentaram resultados maiores que a nota estadual.

É bem verdade que os dados mencionados poderiam criar certo otimismo em relação aos 
municípios com os melhores índices que compõem a o território de identidade em destaque. Mas, novamente, a distância em relação à melhor nota do estado para os anos finais se mostra significativa, visto que o município de Ibitiara apresentou para o ano de 2009 Ideb de 4,6. Essas séries de informações referentes ao Ideb apontam para diversas reflexões acerca das políticas educacionais nos diferentes municípios aqui comentados. Se analisarmos a distribuição do PIB no estado, podemos perceber, de acordo com a tabela 10, que os municípios mais ricos não são necessariamente os que apresentam melhores resultados no que se refere aos dados educacionais aqui comentados.

Tabela 10- Cinco maiores municípios em relação ao PIB Bahia - 2007

\begin{tabular}{|c|c|}
\hline Município & PIB (R\$ milhão) 2008 \\
\hline Salvador & 26.727 .132 \\
\hline Camaçari & 10.401 .520 \\
\hline São Francisco do Conde & 7.144 .211 \\
\hline Feira de Santana & 4.721 .367 \\
\hline Candeias & 2.479 .571 \\
\hline
\end{tabular}

Fonte: SEI 2010a, adaptado pelos autores.

Entre os cinco melhores municípios em relação ao PIB encontramos três municípios pertencentes ao Território de Identidade Metropolitano de Salvador. No entanto estes municípios não chegam ao menos a figurar entre os melhores do estado no que tange os resultados das suas respectivas notas no Ideb, e se tomarmos a título de exemplo apenas a cidade de Salvador, percebe-se que a disparidade entre sua riqueza e seus resultados no Ideb se mostram muito aquém do que se poderia esperar.

O IDS demonstrado na tabela 11 também nos traz resultados relevantes, pois os municípios que apresentam os melhores índices não são os mesmos quando o assunto é o Ideb. Salvador é mais uma vez um exemplo claro, o que demonstra que no IDS a questão educacional não alcança tanto peso como as outras variáveis que compõe o índice em destaque.

Tabela 11- Índice de Desenvolvimento Social do Território de Identidade Metropolitano de Salvador - 2006

\begin{tabular}{|c|c|c|}
\hline Município & IDS 2006) & Posição \\
\hline Lauro de Freitas & $5.303,97$ & 1 \\
\hline Salvador & $5.276,69$ & 8 \\
\hline Madre de Deus & $5.150,43$ & 11 \\
\hline Camaçari & $5.134,40$ & 13 \\
\hline Vera Cruz & $5.128,53$ & 31 \\
\hline Dias D'Ávila & $5.084,72$ & 47 \\
\hline Candeias & $5.067,42$ & 49 \\
\hline Salinas das Margaridas & $5.065,81$ & 54 \\
\hline Itaparica & $5.059,52$ & 81 \\
\hline Simões Filho & $5.038,81$ & \\
\hline
\end{tabular}

Fonte: SEI 2010b, adaptado pelos autores.

Exposto esses dados, podemos sintetizar que, de fato, para a realidade regional em destaque, não é o município que empresta seu nome ao Território de Identidade o detentor dos melhores resultados do Índice de Desenvolvimento da Educação Básica. Embora Salvador tenha um papel fundamental na dinâmica metropolitana, no que tange os resultados aqui salientados a mesma não se apresenta em destaque, ou ao menos em destaque positivo, como possivelmente poderia se pensar. E mais, ao que parece o fato de pertencer ao Território

Geografia Ensino \& Pesquisa, v. 17, n.2 p.7287, mai/ago. 2013

Santos, L.; Borowski, L.; Dias, C.

ISSN $2236-4994$ 
de Identidade Metropolitano de Salvador não favorece consideravelmente algum município em relação ao seu Ideb, visto que no território em questão não encontramos os melhores resultados estaduais. Todavia, outras relações - ainda no temário educacional - poderiam ser aprofundadas e sendo assim esse último questionamento deve ser relativizado.

Ainda deve-se pontuar que as considerações aqui colocadas devem ser pensadas dentro de um todo social, onde atua uma série de fatores que facilitam ou retardam um adequado bem estar social. Nas palavras de Santos,

a relação entre atividades e serviços cuja utilização supõe a presença do usuário no lugar, como a educação ou a saúde, ajuda a explicar a queda da qualidade de vida na aglomeração e a acessibilidade cada vez menor a tais serviços dos estratos mais pobres. (SANTOS, 1990, p.59)

Algumas relativizações devem ser feitas a esse respeito, pois assim como tais relações entre atividades sociais e serviços podem resultar em discrepâncias sociais cada vez mais evidentes, elas podem também mostrar-se como possibilidades de mudanças. E é a partir deste viés que se torna possível o planejamento adequado das políticas públicas aqui analisadas.

\section{Considerações finais}

Os avanços no quadro educacional brasileiro nas últimas décadas são inegáveis e merecem o devido destaque. Em contrapartida, estes avanços tiveram reflexos distintos de acordo com cada realidade regional e local brasileira, fato que nos permite questionar quais as principais variáveis que constroem esta diferenciação, além de ampliar o debate sobre quais os próximos passos a serem estabelecidos em direção ao desenvolvimento pleno da educação brasileira.

Os índices aqui analisados nos dão pistas sobre o que pode ou não influenciar na qualidade da Educação Básica, nas diferentes escalas de abordagens, e apontam para fatores tais como planejamento, princípios pedagógicos e autonomia das unidades escolares, além daqueles, já muito citados, fatores sócio-econômicos.

Ratificamos a importância de um debate ampliado, tanto nas instituições acadêmicas como nas próprias instituições de Ensino Básico, no qual toda a sociedade esteja integrada, junto aos gestores escolares, professores, alunos e familiares. Afinal, umas das pistas encontradas para um bom desempenho escolar são, justamente, as chamadas "redes de aprendizagem", através da troca de experiências pedagógicas positivas e da difusão das mesmas.

Neste ponto torna-se importante a análise e o planejamento regional, não só atentando para fatores econômicos, como tem sido predominante, mas para manter em cada região - e entre elas - uma contínua troca de experiências sociais positivas. O conceito de região, de que tanto se ocupou e ainda se ocupa a Geografia, hoje ganha novos rumos e um deles encontra força, justamente, em meio à organização espacial em redes, podendo configurar-se, cada região, como nós de uma mesma trama. O desenvolvimento espacial em redes não implica, entretanto, em uma homogeneidade territorial, o caráter desigual do desenvolvimento espacial

Geografia Ensino \& Pesquisa, v. 17, n.2 p. 72-87, mai./ago 2013

Análise socio-espacial sobre alguns indicadores da educação pública no ensino fundamental do estado da Bahia sempre se fará presente, mas é importante que não se perca de vista que, assim como as redes servem aos interesses hegemônicos, servem também para a difusão de tais práticas sociais positivas.

\section{Referências bibliográficas}

BAHIA, Decreto n 12354 de 25 de agosto de 2010. Institui o Programa de Territórios de Identidade e dá outras providências. Diário Oficial Salvador, 25 de agosto, 2010. Disponível em: http://www.jusbrasil.com.br/legislacao/1024959/decreto-12354-10-bahia-ba 
Acesso: janeiro de 2012.

BEZZI, Meri Lourdes. Região: Uma (re) visão historiográfica - Da gênese aos novos paradigmas. Santa Maria: UFSM, 2004.

IBGE. Síntese de Indicadores Sociais. Uma análise das condições de vida da população brasileira. Estudos e Pesquisas: Informação Demográfica e Sócioeconômica. No 27. Rio de Janeiro: IBGE, 2010.

INEP. Estatísticas do Ideb. 2010. Disponível em: http:/ /www.portalideb.inep.gov.br/index. php?option $=$ com_content\&view $=$ article\&id $=43 \&$ Itemid $=7$ Acesso: janeiro de 2012

MOREIRA, Ruy. Da região à rede e ao lugar: a nova realidade e o novo olhar geográfico sobre o mundo. Revista Etc (UFF): Rio de Janeiro. v. 1, n. 1(3), p. 55 - 70, 2007.

MEC. Redes de Aprendizagem: Boas práticas de municípios que garantem o direito de aprender. 2008

SANTOS, Milton; ELIAS, Denise. Metamorfoses do espaço habitado: fundamentos teóricos e metodológicos da geografia. São Paulo, SP: Hucitec, 1988.

SANTOS, Milton. Metrópole corporativa fragmentada: o caso de São Paulo. São Paulo: Nobel/Secretaria de Estado da Cultura, 1990.

SILVA, Sylvio Carlos Bandeira de Mello; SILVA, Barbara-Christine Nentwig. Estudos sobre Globalização, Território e Bahia. Salvador: UFBA, 2003.

SUPERINTENDÊNCIA DE ESTUDOS ECONÔMICOS E SOCIAIS (SEI). Produto Interno Bruto dos Municípios: Série 1999-2007. Salvador: SEI, 2010a.

Estatística dos municípios baianos. v. 6. Salvador: SEI, 2010b.

\section{Correspondência:}

\section{Leandro Santos}

E-mail: lopesfiuza@hotmail.com

Recebido em 25 de março de 2012.

Revisado pelo autor em 14 janeiro de 2013.

Aceito para publicação em 14 de fevereiro de 2013.

Geografia Ensino \& Pesquisa, v. 17, n.2 p.7287, mai/ago. 2013

Santos, L.; Borowski, L.; Dias, C. 